\title{
Akses Internet di Wilayah Laut dan Kepulauan Menggunakan WiFi Long Range
}

\author{
Yurika Nantan $^{* 1}$, Zahir Zainuddin ${ }^{1}$, Wardi $^{1}$ \\ ${ }^{1}$ Departemen Teknik Elektro, Fakultas Teknik, Universitas Hasanuddin \\ J1. Poros Malino Km.6, Bontomarannu, Gowa, Sulawesi Selatan, 92171 \\ *Email: yurika.nantan@gmail.com
}

\begin{abstract}
Abstrak
Sebagai negara kepulauan terbesar di dunia, Indonesia memiliki sumber daya alam yang besar di wilayah laut dan kepulauan. Wilayah lautan dan kepulauan yang ditetapkan penggunaannya bagi berbagai sektor kegiatan membutuhkan pemantauan dari berbagai aspek. Kegiatan pemantauan kapal sangat bermanfaat dalam aktifitas pelayaran untuk mengetahui informasi kapal yang sedang berlayar sehubungan dengan kondisi lapangan yang ada utamanya saat cuaca buruk. Untuk melakukan kegiatan pemantauan kapal pada wilayah laut diperlukan konektivitas internet yang dapat menjangkau seluruh wilayah laut dan kepulauan. Penelitian ini menyajikan pemanfaatan teknologi Wireless Fidelity (WiFi) Long Range pada frekuensi bebas $2.4 \mathrm{GHz}$ dalam bidang maritim untuk mendukung sistem monitoring kapal yang sedang berlayar pada wilayah laut dan kepulauan sekitar yang tidak mendapat layanan internet. Penggunaan Wi-Fi Long Range pada frekuensi $2.4 \mathrm{GHz}$ dipakai sebagai perpanjangan koneksi layanan data dalam bidang komunikasi maritim yang diperoleh dari Base Tranceiver Station (BTS) terdekat. Pembaruan sistem ini terletak pada sistem Wi-Fi jarak jauh yang dipasang secara tetap di wilayah kepulauan atau pada buoy yang berada di lautan sehingga layanan internet dapat dimanfaatkan secara bersamaan oleh kapal-kapal khususnya kapal nelayan yang berada di sekitarnya untuk mengirimkan informasi penting yang berkaitan dengan pelayaran seperti posisi kapal melalui Global Positioning System (GPS) pada Mobile Phone (MS). Sistem yang diimplementasikan terbukti mampu memperpanjang koneksi layanan data sejauh $8 \mathrm{~km}$.
\end{abstract}

\begin{abstract}
As the largest archipelago country in the world, Indonesia has great natural resources in marine and island areas. The territorial waters and islands that are deployed for various sectors of activities require monitoring of various aspects. The ship monitoring activity is very useful in shipping activities to find out the ship's information being sailed in relation to the field conditions that exist mainly in bad weather. To conduct ship monitoring activities in the sea area internet connectivity is required that can reach all marine areas and islands. This study presents the utilization of Long Range Wireless Fidelity (Wi-Fi) technology at $2.4 \mathrm{GHz}$ free frequency in the maritime field to support ship monitoring systems that are sailing on marine and adjacent islands that do not get internet service. The use of Long Range Wi-Fi at $2.4 \mathrm{GHz}$ frequency is used as an extension of data service connection in maritime communications obtained from the nearest Base Tranceiver Station (BTS). This system update lies in long-distance Wi-Fi systems installed permanently in archipelagic areas or on buoys located in the oceans so that internet services can be utilized simultaneously by ships, especially fishing vessels located in the vicinity to transmit important information related to voyage such as ship position via Global Positioning System (GPS) on Mobile Phone (MS). Implemented system proved able to extend the data service connection as far as $8 \mathrm{~km}$.
\end{abstract}

Kata-kunci: Wi-Fi Long Range, buoy, Global Positioning System, Base Tranceiver Station, sistem pemantauan kapal.

\section{Pendahuluan}

Indonesia dikenal sebagai negara kepulauan terbesar di dunia dengan jumlah pulau mencapai 17.508 dan garis pantai sepanjang $81.000 \mathrm{~km}$ yang menyimpan kekayaan sumber daya alam laut yang besar. Kawasan pesisir dan lautan yang dinamis tidak hanya memiliki potensi sumber daya, tetapi juga memiliki potensi bagi pengembangan berbagai aktivitas pembangunan yang bersifat ekstrasi seperti industri, pemukiman, konservasi dan lain sebagainya. Dengan adanya pengelolaan diharapkan sumber daya alam ini dapat dimanfaatkan terus-menerus untuk kemakmuran rakyat.

Sehubungan dengan kegiatan pengelolaan sumber daya alam, dipelukan pemantauan dari berbagai aspek. Salah satunya yaitu pemantauan kapal yang sangat bermanfaat dalam aktifitas pelayaran untuk mengetahui informasi kapal 
yang sedang berlayar sehubungan dengan kondisi lapangan yang ada utamanya saat cuaca buruk.

Sistem pemantauan kapal sangat bermanfaat dalam aktifitas pelayaran untuk mengetahui informasi kapal yang sedang berlayar sehubungan dengan kondisi lapangan yang ada utamanya saat cuaca buruk. Lamanya waktu yang dipakai nelayan untuk bepergian mencari ikan di wilayah laut lepas mendorong dikembangkannya berbagai penelitian dibidang komunikasi maritim. Banyak teknologi telekomunikasi yang dapat digunakan untuk melakukan kegiatan pemantauan kapal mulai dari teknologi konvensional sampai modern.

Teknologi satelit [1] dan radar [2] juga telah dilakukan, akan tetapi masih memiliki kendala utama diantaranya efisiensi biaya yang tinggi dan ukuran perangkat yang digunakan juga relatif cukup besar. Solusi yang paling efektif adalah dengan memanfaatkan sistem komunikasi pemancar stasiun radio terdekat yang berada di daratan. Pemanfaatan tower BTS terakhir menjadi solusi konektifitas untuk dapat terhubung ke jaringan internet.

Pemanfaatan sistem ini diharapkan dapat memudahkan aktifitas pemantauan kapal pada wilayah laut ataupun kepulauan yang belum tejangkau sinyal. Hal ini karena pengguna kapal kebanyakan menggunakan mobile phone sebagai alat komunikasi utamanya. Banyak penelitian yang memanfaatkan sistem komunikasi radio di laut seperti pemanfaatan teknologi Wimax [3] [4]. Akan tetapi perkembangan teknologi Wimax di Indonesia masih terkendala pada regulasi pemakaian frekuensi.

Penerapan sebuah bridge maricom [5] dengan berbagai teknik untuk meningkatkan performansinya [6] dan gabungan teknologi broadband yang lain dalam proyek bluecom+ [7] juga dilakukan untuk mendukung komunikasi pada wilayah laut yang hemat biaya dan memiliki akses data rate yang tinggi. Hal ini masih memiliki kekurangan disisi fleksibilitas seperti sistem yang dibuat dipasang pada masingmasing kapal sehingga berdampak pada biaya yang cukup tinggi dan tidak memungkinkan untuk kapal berukuran kecil seperti kapal nelayan untuk memilikinya.
Dari penelitian [8], membandingkan teknologi Wi-Fi dan LoRa pada frekuensi kerja 2.4 GHz. Dari hal tersebut, LoRa menghasilkan jarak jangkauan yang jauh dengan konsumsi daya yang rendah, karena tingkat pengiriman datanya rendah. Sama dengan [8], [9] menggunakan teknologi Wi-Fi LR namun bekerja pada frekuensi $5.8 \mathrm{GHz}$. Hal tersebut diaplikasikan pada lingkup maritim secara point to point link antara kapal dan stasiun pemancar yang berada di daratan. Hasil yang diperoleh adalah jarak jangkauan hingga $7 \mathrm{Km}$ pada pengiriman data $1 \mathrm{Mbit} / \mathrm{s}$. Merujuk pada keduanya, penelitian ini membahas perancangan sistem komunikasi wireless menggunakan Wi-Fi LR dengan frekuensi kerja 2,4 GHz pada wilayah laut dan kepulauan yang belum terjangkau sinyal dengan memanfaatkan penyedia jaringan komunikasi mobile terdekat yang sudah ada di daratan. Frekuensi 2,4 GHz dipilih karena mampu menyediakan rentang maksimum yang sama dengan kecepatan data. Penerapan sistem ini mampu menghasilkan jarak jangkauan sejauh $8 \mathrm{~km}$, sehingga diharapkan daerah laut dan kepulauan di Indonesia yang belum terjangkau sinyal BTS ini dapat dijangkau seluruhnya secara multihop dari setiap perangkat yang terpasang di pulau ataupun pada buoy secara tetap yang akan memudahkan pengguna kapal untuk menyampaikan informasi penting seperti lokasi kapal ke stasiun pemancar yang berada di daratan untuk kegiatan pemantauan kapal.

\section{Desain Sistem}

Pada bagian ini memberikan gambaran tentang perancangan sistem dan arsitektur jaringan yang digunakan untuk mendukung komunikasi maritim dalam rangka melakukan pemantauan posisi kapal-kapal yang sedang melakukan pelayaran. Untuk dapat memberikan akses internet yang hemat biaya di wilayah laut maka perangkat yang digunakan pada penelitian ini merupakan perangkat yang menggunakan standar teknologi akses nirkabel pada umumnya yang hemat biaya seperti Wi-Fi LR produksi Ubiquiti dengan rentang frekuensi kerja $2,4 \mathrm{GHz}$. Adapun spesifikasi dan jenis perangkat yang digunakan di tampilkan pada Tabel 1 [10]. 
Tabel 1. Spesifikasi perangkat

\begin{tabular}{|c|c|}
\hline Nama Perangkat & Spesifikasi \\
\hline Ubiquiti NanoStation M2 & $\begin{array}{l}\text { Operating Frequency : } 2412-2462 \mathrm{MHz} \\
\text { Gain : } 10.4-11.2 \mathrm{dBi} \\
\text { Sensitivity : }-75 \mathrm{up} \text { to }-96 \mathrm{dBm} \\
\text { Power Supply (PoE) : } 24 \mathrm{~V}, 0.5 \mathrm{~A} \\
\text { Operating Temperature : }-30 \text { to } 75^{\circ} \mathrm{C} \\
\left(-22 \text { to } 167^{\circ} \mathrm{F}\right) \\
\text { Beamwidth : } 55^{\circ}(\mathrm{H}-\text { pol }) / 53^{\circ}(\mathrm{V}-\text { pol }) \\
\text { Polarization : Dual Linear } \\
\text { Networking Interface : } 10 / 100 \text { Ethernet } \\
\text { Ports (2). }\end{array}$ \\
\hline Ubiquiti Unifi Mesh & $\begin{array}{l}\text { Model: UAP-AC-M-PRO } \\
\text { Wi-Fi Standards : } 802.11 \mathrm{a} / \mathrm{b} / \mathrm{g} / \mathrm{n} / \mathrm{ac} \\
\text { Networking Interface }: 10 / 100 / 1000 \\
\text { Ethernet Ports (2) } \\
\text { Power Supply : } 48 \mathrm{~V}, 0.5 \mathrm{~A} \text { PoE Gigabit } \\
\text { Adapter } \\
\text { Maximum TX Power : } 22 \mathrm{dBm} \\
\text { Operating Temperature : }-40 \text { to } 70^{\circ} \mathrm{C} \\
\left(-40 \text { to } 158^{\circ} \mathrm{F} \text { ) }\right. \\
\text { BSSID : Up to Four per Radio } \\
\text { Antennas : } 8 \mathrm{dBi}\end{array}$ \\
\hline Ubiquiti Rocket M2 & $\begin{array}{l}\text { Operating Frequency : } 2412-2462 \mathrm{MHz} \\
\text { Power Output : } 28 \mathrm{dBm} \\
\text { Operating Temperature : }-30 \text { to } 75^{\circ} \mathrm{C} \\
\left(-22 \text { to } 167^{\circ} \mathrm{F}\right) \\
\text { Gain : } 11-16 \mathrm{dBi} \\
\text { RF Connections : RP-SMA (2) } \\
\text { Networking Interface : (1) } 10 / 100 \mathrm{Mbps} \\
\text { Power Supply : } 24 \mathrm{~V}, 1 \mathrm{~A} \text { PoE Adapter }\end{array}$ \\
\hline
\end{tabular}

Berdasarkan data masukan pada tabel I, maka dapat dilakukan perhitungan link budget dengan menggunakan pendekatan model Okumura-Hata. Besarnya daya pada penerima $\left(\mathrm{P}_{\mathrm{RX}}\right)$ merupakan hasil penjumlahan daya pada pemancar $\left(\mathrm{P}_{\mathrm{TX}}\right)$ dengan penguatan yang ada $\left(\mathrm{G}_{\mathrm{TX}}\right.$ dan $\left.\mathrm{G}_{\mathrm{Rx}}\right)$, dikurangi dengan semua rugi yang terjadi pada sistem. Dapat dilihat pada Persamaan (1).

$$
\mathrm{P}_{\mathrm{RX}}=\mathrm{P}_{\mathrm{Tx}}+\mathrm{G}_{\mathrm{TX}}-\mathrm{L}_{\text {cable }}-\mathrm{L}_{\mathrm{FSL}}+\mathrm{G}_{\mathrm{Rx}}
$$

Adapun rugi-rugi ruang bebas yang terjadi merupakan penjumlahan antara jarak pemancar dan penerima (d) dengan frekuensi (f) seperti pada Persamaan (2).

$$
\mathrm{L}_{\mathrm{FSL}}=32,4+20 \log \mathrm{d}+20 \log \mathrm{f}
$$

\subsection{Perancangan Sistem}

Perancangan sistem pada wilayah laut dan kepulauan secara keseluruhan diperlihatkan pada Gambar 1.

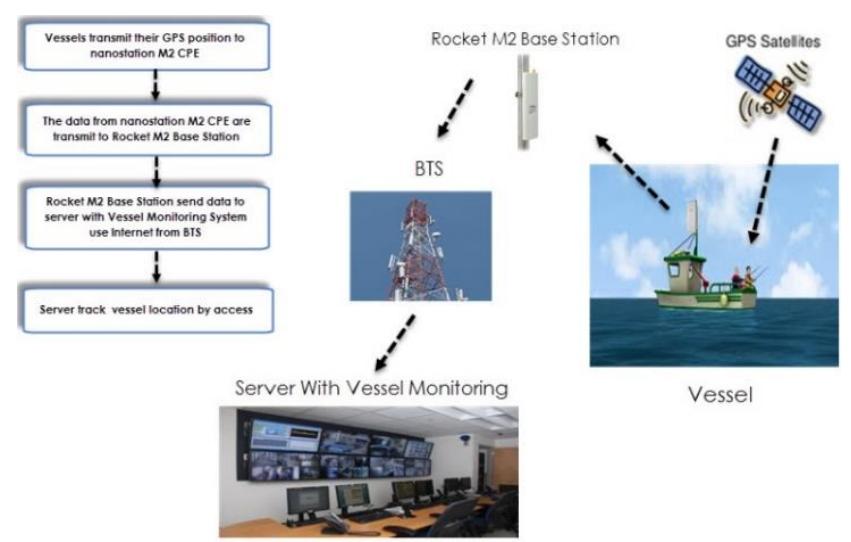

Gambar 1. Perancangan sistem

Koneksi Wi-Fi standar menggunakan unifi access point (AP) diperoleh oleh mobile phone atau GPS kapal yang berasal dari Wi-Fi LR yang diletakkan pada wilayah kepulauan atau buoy yang tidak terjangkau sinyal sebagai Customer Premises Equipment (CPE). Adapun koneksi internet yang diperoleh diambil dari jaringan BTS terdekat dengan menggunakan rocket M2 sebagai Base Station (BS) yang diletakkan di sekitar daratan yang masih dalam jangkauan sinyal BTS sehingga menghasilkan konektivitas secara point to point ataupun point to multipoint.

Pemasangan perangkat pada pulau terlihat pada Gambar 2. Pada pemasangan perangkat sangat penting untuk dilakukan settingan parameter fisik sehingga antara BS dan CPE dapat saling berkomunikasi dengan baik.

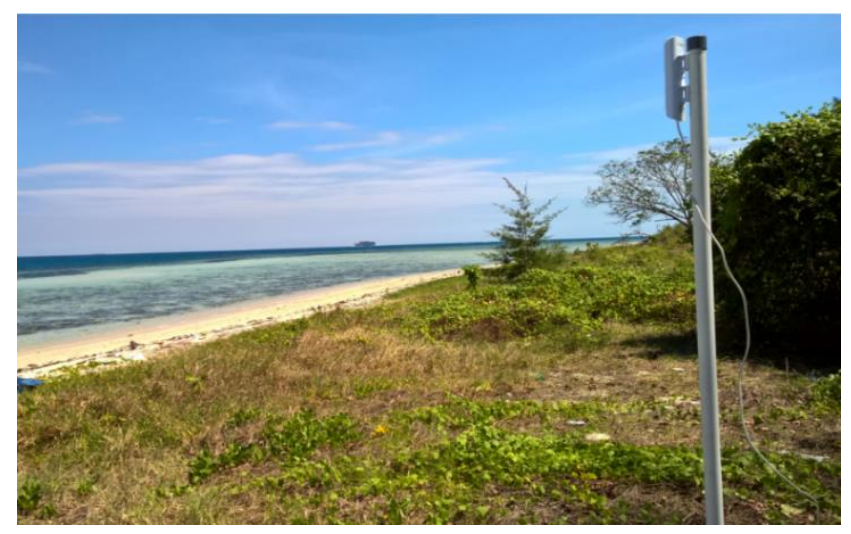

Gambar 2. Instalasi perangkat ubiquiti

Besarnya jarak yang mampu dihasilkan antara BS dan CPE tergantung pada kondisi lingkungan dan parameter fisik dari antena pada saat percobaan dilakukan yang nantinya 
dijadikan acuan perpanjangan konektivitas internet kearah laut.

\subsection{Arsitektur Jaringan}

Base Station yang berada di daratan akan menyediakan koneksi point to multipoint kearah $\mathrm{CPE}$ yang nantinya akan meneruskan jaringan Wi-Fi ke arah mobile phone menggunakan topologi mesh. Hal ini akan memaksimalkan pemanfaatan jaringan secara bersamaan dalam rangka mendukung layanan monitoring kapal di wilayah laut dan kepulauan. Gambar 3 menunjukkan asitektur jaringan yang akan digunakan.

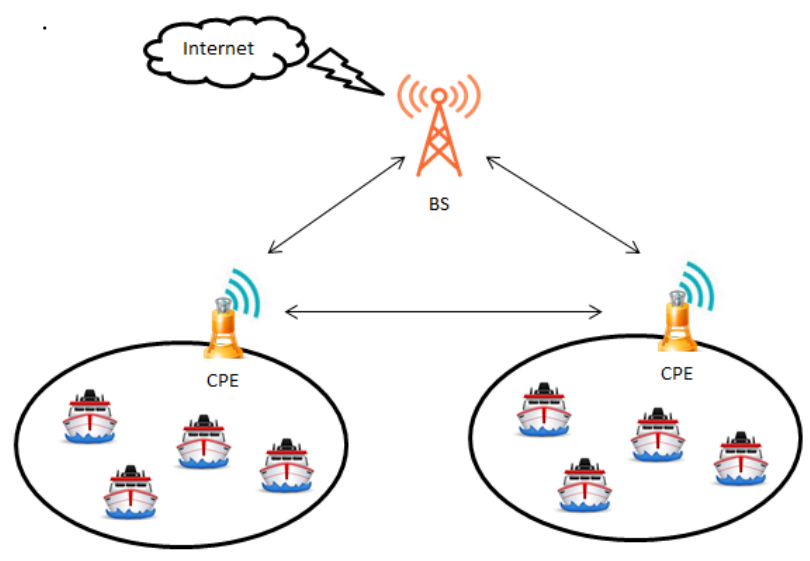

Gambar 3. Arsitektur jaringan.

Kapal-kapal yang sudah terdaftar dalam sistem dan berada dalam jangkauan CPE dapat dipantau dengan mudah posisinya dengan menerapkan sistem ini. Informasi posisi kapal yang diperoleh CPE terdekat dari kapal selanjutnya diteruskan ke CPE lain atau dapat langsung ke BS yang berada di daratan.

\section{Hasil Penelitian}

Uji coba lapangan dilakukan pada daerah pesisir pantai Makassar, Indonesia. Pengujian dilakukan dengan menempatkan BS pada pesisir pantai dan CPE pada kapal. Data pengukuran jarak maksimum diambil dengan cara $\mathrm{CPE}$ bergerak menjauhi BS sampai titik dimana sinyal BS sudah tidak dapat diterima. Setiap titik merupakan perhentian untuk mengambil data posisi kapal dan level sinyal dengan mengaktifkan aplikasi monitoring dan aplikasi pendukung pengukuran pada mobile phone. Dari keseluruhan titik pengambilan data yang dilakukan diperoleh rentang jarak konektivitas internet maksimal dapat mencapai $8 \mathrm{~km}$. Jarak diukur menggunakan jarak udara antara titik awal dengan titik akhir seperti Gambar 4.

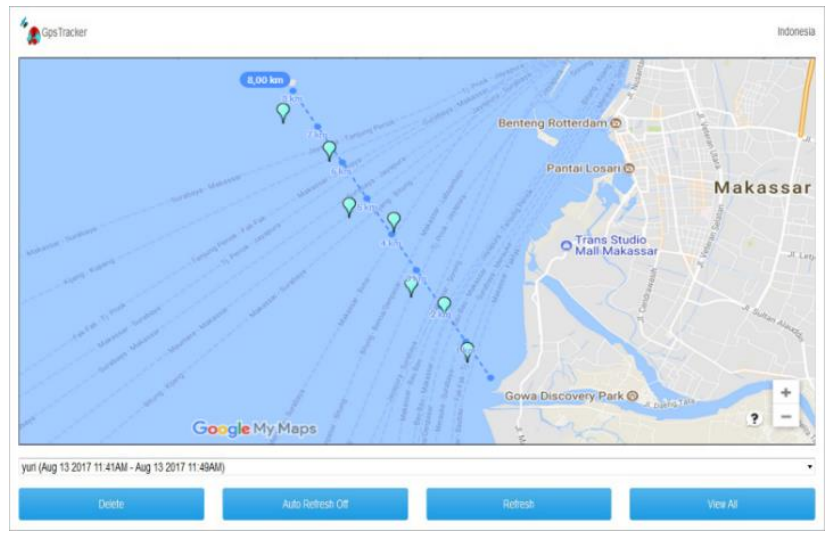

Gambar 4. Hasil monitoring kapal

Pada pengujian ini, antena BS diletakkan setinggi $5 \mathrm{~m}$ dan antena CPE $2 \mathrm{~m}$ dengan tilt antena sebesar $0^{\circ}$. Pengujian lapangan ini dilakukan untuk mengetahui jarak maksimum sinyal dari pemancar BS yang masih dapat diterima oleh penerima CPE. Hasilnya akan di bandingkan dengan perhitungan link budget yang diperoleh dari Persamaan (1). Jika hasil dari level sinyal pada penerima lebih baik dari nilai level minimum penerimaan sinyal penerima pada datasheet maka sistem dinyatakan layak. Hasil yang diperoleh bertujuan untuk membuktikan kelayakan dari solusi komunikasi wireless yang diberikan.

Adapun besarnya level sinyal yang diukur pada penerima ditunjukkan pada Tabel 2 . Pengukuran ini diambil menggunakan aplikasi android pada mobile phone.

Tabel 2. Hasil pengukuran kuat sinyal berdasarkan jarak dari BS ke CPE

\begin{tabular}{cccc}
\hline Jarak (km) & $\begin{array}{c}\text { Tinggi } \\
\text { Antenna } \\
\text { Pemancar } \\
\text { BS (m) }\end{array}$ & $\begin{array}{c}\text { Tinggi } \\
\text { Antenna } \\
\text { Penerima } \\
\text { CPE (m) }\end{array}$ & $\begin{array}{c}\text { Level Sinyal } \\
(\mathbf{d B m})\end{array}$ \\
\hline 1 & 5 & 2 & -58 \\
\hline 2 & 5 & 2 & -64 \\
\hline 4 & 5 & 2 & -70 \\
\hline 5 & 5 & 2 & -72 \\
\hline 6 & 5 & 2 & -73 \\
\hline 8 & 5 & 2 & -76 \\
\hline
\end{tabular}


Dari persamaan (1) dihitung link budget sesuai data masukan pada Tabel 1, hasilnya seperti pada Gambar 5.

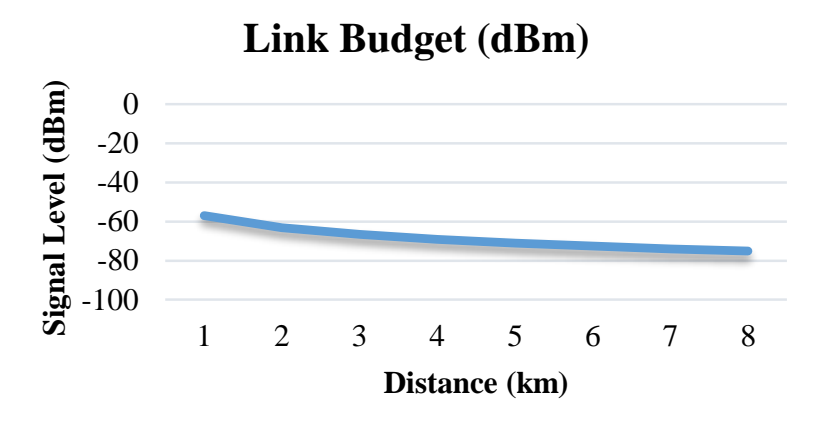

Gambar 5. Perhitungan link budget menggunakan model okumura-hata

Pada jarak $8 \mathrm{Km}$ hasil perhitungan link budget sebesar $-75 \mathrm{dBm}$ sedangkan pada hasil pengukuran lapangan sebesar -76 dengan selisih sebesar $1 \mathrm{dBm}$ saja. Jika dilihat sensitivitas penerimaan perangkat sebesar $-96 \mathrm{dBm}$ sampai $75 \mathrm{dBm}$, maka hasil perolehan data lapangan dan perhitungan link budget level sinyal yang diterima masih masuk pada level minimum sensitivitas penerimaan perangkat. Hal ini berarti sistem masih layak.

Daerah fresnel yang masih dapat dicapai pada keadaan LOS dengan asumsi permukaan bumi lengkung, jarak antara BS dan CPE $8 \mathrm{Km}$ dan tinggi antena CPE $2 \mathrm{~m}$ dan BS $5 \mathrm{~m}$ ditunjukkan pada gambar 6. Pada jaringan wireless diambil nilai $60 \%$ dari radius daerah fresnel pertama sebagai daerah yang bersih.

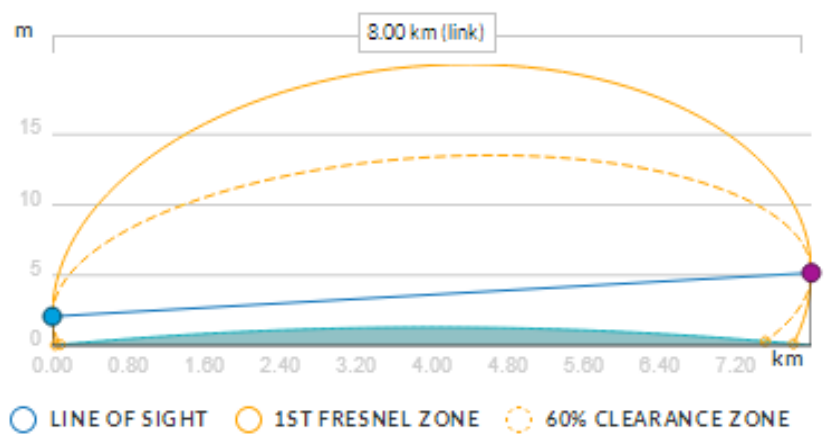

Gambar 6. Daerah fresnel

Adapun penggunaan kanal yang paling optimal yang dihasilkan sistem berada pada kanal 6 yang ditampilkan Gambar 7.

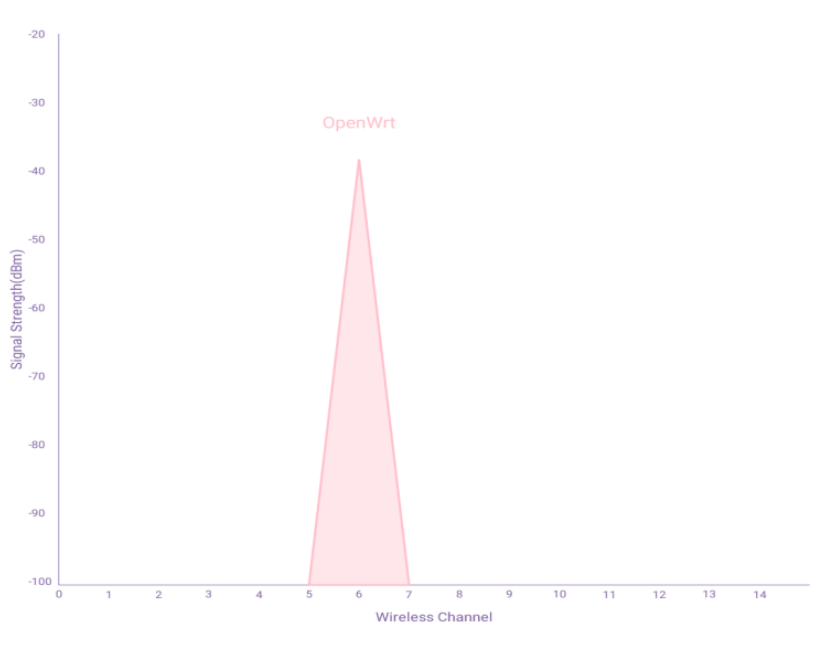

Gambar 7. Penggunaan kanal

Pada sisi mobile phone pengguna juga dilakukan pengujian kecepatan data, hasilnya diperoleh data kecepatan download sebesar 2,43 Mbps dan kecepatan upload sebesar 1,92 Mbps yang berasal dari pancaran sinyal Wi-Fi yang access point seperti yang diperlihatkan pada Gambar 8.

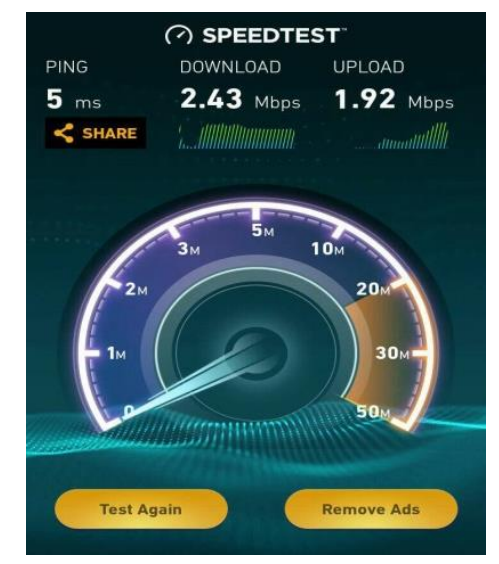

Gambar 8. Hasil speedtest

\section{Kesimpulan}

Penelitian ini mengaplikasikan penggunaan WiFi LR sebagai solusi perpanjangan koneksi layanan data berbiaya rendah dari daratan ke wilayah laut dan kepulauan yang tidak terjangkau sinyal. Pengukuran level sinyal pada $\mathrm{CPE}$ yaitu sebesar $-76 \mathrm{dBm}$. Nilai ini masih berada pada range sensitivitas penerimaan perangkat yaitu $-96 \mathrm{dBm}$ sampai $-75 \mathrm{dBm}$ sehingga CPE masih dapat menerima sinyal dari BS dengan baik. Pemanfaatan sistem untuk 
melakukan monitoring kapal juga telah dilakukan sehingga dimasa mendatang dirasakan perlu untuk dikembangkan sistem layanan masyarakat yang dapat membantu masyarakat kepulauan seperti kesehatan dan layanan Pemerintah lainnya dan melakukan analisa unjuk kerja sistem secara mendalam.

\section{Referensi}

[1] E. N. Nasser, "Multi mission low earth orbit equatorial satellite for Indonesian regions: Telecommunication payload," Proceeding - ICARES 20142014 IEEE Int. Conf. Aerosp. Electron. Remote Sens. Technol., no. c, pp. 121-126, 2014.

[2] J. Stastny, S. Cheung, G. Wiafe, K. Agyekum, and H. Greidanus, "Application of RADAR Corner Reflectors for the Detection of Small Vessels in Synthetic Aperture Radar," IEEE J. Sel. Top. Appl. Earth Obs. Remote Sens., vol. 8, no. 3, pp. 1099-1107, 2015.

[3] M. S. Choi et al., "Ship to shore maritime communication for e-Navigation using IEEE 802.16e," Int. Conf. ICT Converg., pp. 759-762, 2013.

[4] J. C. Reyes-Guerrero, M. Bruno, L. A. Mariscal, and A. Medouri, "Buoy-to-ship experimental measurements over sea at $5.8 \mathrm{GHz}$ near urban environments," Mediterr. Microw. Symp., pp. 320324, 2011.

[5] H. Kim, J. Choi, D. Yoo, B. Jang, and K. Chong, "Implementation of MariComm Bridge for LTEWLAN Maritime Heterogeneous Relay Network,” pp.
3-7, 2015.

[6] D. Yoo, H. Kim, J. Choi, B. Jang, and S. Ro, "A Novel Antenna Tracking Technique for Maritime Broadband Communication ( MariComm ) System," pp. 1-5, 2015.

[7] R. Campos, T. Oliveira, N. Cruz, A. Matos, and J. M. Almeida, "BLUECOM+: Cost-effective broadband communications at remote ocean areas," Ocean. 2016 - Shanghai, 2016.

[8] D. H. Kim and J. Y. Lim, "Using Wi-Fi and LoRa," 2016 Ieee, pp. 1-3, 2016.

[9] M. J. Lopes, F. Teixeira, J. B. Mamede, and R. Campos, "Wi-Fi Broadband Maritime Communications Using 5.8 GHz Band," pp. 5-9, 2014.

[10] I. Outdoor, L. Industrial, and P. Link, "Indoor/Outdoor airMAX ${ }^{\circledR}$ CPE.” 